\title{
PENERAPAN HYGIENE SANITASI DI RUMAH MAKAN MINANG SIMPANG AMPEK PANJER KOTA DENPASAR TAHUN 2021
}

\author{
Dewi Puspita Sari ${ }^{1}$, I Nyoman Gede Suyasa ${ }^{2}$
}

\begin{abstract}
A restaurant is one of the places visited by the general public with special attention in the field of sanitation. Based on preliminary observations made by some food handlers, they do not use plastic gloves when processing food. This study aims to see the state of sanitation hygiene in the Minang Simpang Ampek Panjer Restaurant, Denpasar City. The type of research used is descriptive research with a survey method. Observation results show that the selection of food ingredients produced is $100 \% .100 \%$ food processing. Storage of $100 \%$ foodstuffs. $100 \%$ finished food storage. Serving $80 \%$ of the production. $80 \%$ personal hygiene result. The application of cleanliness as a result of the calculation meets the requirements, namely 93.33\%. Food handlers should use plastic gloves when processing food. Serving food should use a food cover so that food is not contaminated with dust, insects, hair or other dirt. Food packaging should use food grade or health-safe packaging such as using banana leaves when wrapping food
\end{abstract}

Keywords: Restaurant; Sanitation Hygiene

\section{PENDAHULUAN}

Rumah Makan sebagai salah satu tempat pengolahan makanan yang menetap dengan segala peralatan dan perlengkapan yang digunakan untuk proses membuat, menyimpan, menyajikan makanan dan minuman bagi umum, dimana orang dapat datang untuk membeli makanan dan minuman di tempat tersebut ${ }^{1}$. Makanan harus diperhatikan hygiene sanitasinya karena apabila tidak diperhatikan dalam pengolahan, penyimpanan, maupun penyajiannya, maka dapat menjadi media penularan penyakit ${ }^{2}$. Hygiene sanitasi makanan minuman yang baik perlu ditunjang oleh kondisi lingkungan dan sarana sanitasi yang baik pula. Keadaan hygiene sanitasi yang buruk dapat mempengaruhi kualitas makanan yang disajikan kepada konsumen ${ }^{3}$. 
Sanitasi adalah suatu usaha pencegahan penyakit yang menitik beratkan kegiatan pada usaha kesehatan lingkungan. Dengan demikian, sanitasi merupakan usaha maupun tindakan dari seseorang terhadap lingkungan sekitarnya agar terkondisi bersih dan sehat ${ }^{4}$. Sanitasi makanan merupakan salah satu bagian yang penting, dalam segala aktivitas kesehatan masyarakat, mengingat adanya kemungkinan penyakit penyakit akibat makanan. Sanitasi makanan meliputi kegiatan usaha yang ditunjukan kepada kebersihan dan kemurnian makanan agar tidak menimbulkan penyakit ${ }^{5}$.

Peningkatan dan pemantapan upaya kesehatan diselenggarakan melalui berbagai macam kegiatan, salah satunya adalah pengamanan makanan dan minuman. Upaya pengamanan makanan dan minuman akan lebih ditingkatkan, untuk mendukung peningkatan dan pemantapan upaya kesehatan. Semua itu merupakan upaya untuk melindungi masyarakat dari makanan dan minuman yang tidak memenuhi persyaratan mutu ${ }^{6}$.

\section{METODE PENELITIAN}

$\begin{array}{clr}\text { Jenis } & \text { Penelitian } & \text { yang } \\ \text { dipergunakan } & \text { adalah penelitian }\end{array}$
deskriptif dengan metode survei. Melalui penelitian deskriptif, penulis berusaha mendeskriptifkan peristiwa dan kejadian yang menjadi pusat perhatian tanpa memberikan perlakuan khusus terhadap peristiwa tersebut ${ }^{7}$.Pengumpulan data dilakukan dengan cara observasi. Unit analisa dalam penelitian ini adalah keadaan hygiene sanitasi rumah makan di Rumah Makan Minang Simpang Ampek Panjer. Pengumpulan data dilakukan dengan wawancara dan observasi keadaan hygiene sanitasi rumah makan di Rumah Makan Minang Simpang Ampek Panjer. Instrumen pengumpulan data menggunakan lembar observasi hygiene sanitasi rumah makan dan perlengkapan alat tulis seperti pulpen, pensil, buku tulis dan kamera handphone untuk mendokumentasikan kegiatan penelitian di lapangan. Teknik pengolahan data dilakukan dengan cara editing, codding, entry dan tabulating. Analisis data diuraikan dengan menggunakan 2 kategori 
adalah memenuhi syarat dan tidak memenuhi syarat. Pada formulir penilaian terdapat 60 item observasi dimana skor tertinggi pada masing masing item adalah 1 dan skor terendah adalah 0 .

\section{HASIL DAN PEMBAHASAN}

\section{Hygiene sanitasi pemilihan bahan makanan}

Hasil pengamatan observasi pemilihan bahan makanan di Rumah Makan Minang Simpang Ampek Panjer Kota Denpasar mendapatkan hasil memenuhi syarat yaitu $100 \%$. Kondisi bahan makanan yang digunakan dalam keadaan baik dan segar, kondisi fisik bahan makanan yang digunakan tidak membusuk, tidak rusak. Bahan makanan yang digunakan di dapatkan dari sumber resmi dan telah terdaftar dalam BPOM. Tidak menggunakan BTP berlebihan, melakukan pengecekan kualitas dan kuantitas bahan makanan. Kualitas bahan makanan yang baik yaitu bahan makanan yang terbebas dari pencemaran termasuk pencemaran kimia seperti pestisida dan juga kerusakan. Lalu pegawai melakukan pemilihan bahan baku makanan. Menurut penelitian yang dilakukan ${ }^{8}$ menyatakan supplier bahan baku yang di pilih adalah supplier yang dapat dipercaya dan di verifikasi oleh pihak yang berwenang melalui pengecekan sumber pasokan.

Pada Rumah makan minang simpang ampek panjer daging dan ayam yang digunakan dalam keadaan baik. Sayuran dan buah - buahan yang di gunakan dalam kondisi baik. Lalu untuk bahan tambah pangan digunakan dalam keadaan baik. Kualitas makanan dapat dilihat melaui ciri - ciri fisik dan mutunya. Kualitas bahan makanan yang baik yaitu bahan makanan yang terbebas dari pencemaran termasuk pencemaran kimia seperti pestisida dan juga kerusakan.

\section{Hygiene sanitasi pengolahan makanan}

Hasil pengamatan observasi pengolahan makanan di Rumah Makan Minang Simpang Ampek Panjer Kota Denpasar mendapatkan hasil yaitu 100\%. Pengolahan makanan di rumah makan minang simpang ampek panjer pada penelitian ini untuk mengolah makanan penjamah makanan 
menggunakan bahan yang baik dan tidak rusak dan bahan makanan di olah dengan baik. Lalu tenaga pengolah memakai pakaian kerja yang bersih, dan baik. Sebelum mengolah makanan pengolah makanan mencuci tangan, peralatan masak yang digunakan tidak dalam keadaan rusak, melakukan cara kerja yang bersih, menggunakan peralatan dengan baik dan peralatan masak mudah dibersihkan. Berdasarkan Keputusan Menteri Kesehatan Republik Indonesia Nomor 1098/Menkes/SK/VII/2003， Semua kegiatan pengolahan makanan harus dilakukan dengan cara terlindung dari kontak langsung dengan tubuh. Perlindungan kontak langsung dengan makanan jadi dilakukan dengan penjepit makanan, sendok garpu dan sejenisnya. Menurut penelitian yang dilakukan ${ }^{9}$ menyatakan pengolahan makanan menjadi makanan jadi adalah tahap utama dalam proses penyediaan makanan. Pengolahan bahan makanan yang diteliti meliputi tiga hal yaitu, cara menjamah makanan, tempat pengolahan, dan peralatan masak yang digunakan.

\section{Hygiene sanitasi penyimpanan bahan makanan}

Hasil pengamatan observasi penyimpanan bahan makanan di Rumah Makan Minang Simpang Ampek Panjer Kota Denpasar mendapatkan hasil yaitu $100 \%$. Kondisi penyimpanan bahan makanan disimpan dalam tempat rak penyimpanan makanan. Kondisi rak penyimpanan bersih, wadah terbuat dari bahan yang aman dan dalam keadaan bersih dan baik. Pada rumah makan bahan makanan disimpan dalam keadaan tertutup, bahan makanan di simpan dalam wadah yang terpisah sesuai jenisnya seperti sayuran atau bumbu masakan disimpan di freezer dan daging ikan disimpan di box pendingin sehingga tidak mengalami kontaminasi pada makanan. Menurut penelitian yang dilakukan ${ }^{8}$ menyatakan, sebelum dilakukan penyimpanan, bahan makanan harus dibersihkan terlebih dahulu. Cara membersihkan bahan makanan yang dapat dilakukan salah satunya adalah dengan mencuci bahan makanan, kemudian dikeringkan agar tidak terdapat air pada bahan makanan, 
dan kemudian dibungkus menggunakan kontainer plastik tertutup yang bersih dan disimpan di ruangan dengan suhu rendah.

\section{Hygiene sanitasi penyimpanan makanan jadi}

Hasil pengamatan observasi penyimpanan makanan jadi di Rumah Makan Minang Simpang Ampek Panjer Kota Denpasar mendapatkan hasil yaitu $100 \%$. Pada rumah makan minang simpang ampek panjer keadaan penyimpan makanan jadi dalam keadaan tertutup, tempat penyimpanan makanan jadi dalam keadaan bersih, makanan jadi terhindar dari binatang pengganggu dan tempat penyimpanan makanan jadi dalam keadaan bersih atau tidak kotor. Makanan tidak rusak, tidak busuk atau basi yang ditandai dari rasa, bau, berlendir, berubah warna, berjamur

Tabel 1

Hasil observasi penyajian makanan berubah aroma, atau adanya cemaran lain. Menurut Permenkes ${ }^{10}$ tentang persyaratan hygiene sanitasi Jasaboga tempat atau wadah penyimpanan harus terpisah untuk setiap jenis makanan jadi dan mempunyai tutup yang dapat menutup sempurna tetapi berventilasi yang dapat mengeluarkan uap air. Makanan jadi tidak dicampur dengan bahan makanan mentah. Suhu dan waktu yang digunakan sesuai dengan persyaratan dan menerapkan prinsip FEFO dan FIFO.

\section{Hygiene sanitasi penyajian makanan}

Hasil pengamatan observasi penyajian makanan di Rumah Makan Minang Simpang Ampek Panjer Kota Denpasar mendapatkan hasil skore 80\% dan dapat dilihat pada tabel 1 berikut :

\begin{tabular}{cccc}
\hline No & Kategori & Frekuensi & Presentase (\%) \\
\hline 1 & Ya & 8 & $80 \%$ \\
2 & Tidak & 2 & $20 \%$ \\
\hline & Total & 10 & $100 \%$ \\
\hline
\end{tabular}

Berdasarkan tabel 1 penilaian hygiene dilakukan menggunakan formulir sanitasi penyajian makanan yang observasi menunjukan bahwa 
penyajian makanan yang memenuhi syarat yaitu $80 \%$. Pada Rumah Makan Minang Simpang Ampek pada saat penyajian makanan tidak dalam keadaan tertutup, sehingga makanan dapat terkontaminasi debu, serangga, rambut dan lainnya. Meja tempat penyajian makanan tidak ditutup dengan kain atau plastik sehingga menyebabkan makanan terkontaminasi oleh Saat penyajian makanan yang perlu diperhatikan adalah agar makanan tersebut terhindar dari pencemaran fisik seperti, rambut, debu, tanah, serangga dan kotoran lainnya. Menurut Kumpulan Modul Kursus Higiene Sanitasi Makanan Dan

Minuman ${ }^{11}$ prinsip penyajian makanan pemisahan wadah artinya setiap jenis makanan ditempakan dalam wadah terpisah masing masing dan diusahakan tertutup. Tujuannya agar makanan tidak terkontaminasi silang, bila satunya tercemar yang lainnya dapat diamankan.

\section{Hygiene sanitasi personal hygiene}

Hasil pengamatan observasi sanitasi personal hygiene di Rumah Makan Minang Simpang Ampek Panjer Kota Denpasar mendapatkan hasil $80 \%$ dan dapat dilihat pada tabel 2 berikut :

Tabel 2

Hasil observasi personal hygiene

\begin{tabular}{cccc}
\hline No & Kategori & Frekuensi & Presentase (\%) \\
\hline 1 & Ya & 8 & $80 \%$ \\
2 & Tidak & 2 & $20 \%$ \\
\hline & Total & 10 & $100 \%$ \\
\hline
\end{tabular}

Berdasarkan tabel 2 penilaian sanitasi personal hygiene yang dilakukan menggunakan formulir observasi menunjukan bahwa personal hygiene yang memenuhi syarat adalah 8 dan tidak memenuhi syarat adalah 2 . Adapun penilaian yang masih belum terpenuhi yaitu, penjamah makanan tidak memakai sarung tangan plastik saat mengolah maupun menyiapkan makanan. Hal ini dikarenakan penjamah makanan merasa tidak terbiasa jika memakai sarung tangan plastik. Penelitian dari ${ }^{12}$ menunjukkan bahwa agar higiene dan sanitasi rumah makan terjaga maka dibutuhkan 
pengawasan pada penjamah makan. Penjamah makanan berperan penting dalam upaya mencegah terjadinya pencemaran terhadap makanan yang akan dikonsumsi oleh masyarakat.
Hasil pengamatan observasi Penerapan Hygiene Sanitasi Di Rumah Makan Minang Simpang Ampek Panjer mendapatkan hasil skore yaitu 93,33\% dan dapat dilihat pada tabel 3 berikut :

\section{Penerapan hygiene sanitasi}

\section{rumah makan}

Tabel 3

Hasil obervasi penerapan hygiene sanitasi di rumah makan

\begin{tabular}{cccc}
\hline No & Kategori & Frekuensi & Presentase (\%) \\
\hline 1 & Ya & 56 & $93,33 \%$ \\
2 & Tidak & 4 & $6,67 \%$ \\
\hline & Total & 60 & $100 \%$ \\
\hline
\end{tabular}

Hasil observasi menunjukkan bahwa penerapan prinsip hygiene sanitasi makanan dengan kategori memenuhi syarat adalah 56 (93,33\%). Prinsip hygiene sanitasi makanan terdiri dari enam prinsip yang terdiri dari pemilihan bahan makanan, penyimpanan bahan makanan, pengolahan makanan, penyimpanan makanan jadi, penyajian makanan dan personal hygiene. Pada penyajian makanan dan personal hygiene masih ada penilaian yang belum terpenuhi yakni pada penyajian makanan masih belum tertutup dan meja makan tidak tertutup oleh taplak meja atau alas meja. Dan pada personal hygiene, penjamah makanan masih belum terbiasa menggunakan sarung tangan plastik untuk mencegah kontaminasi pada makanan. Masalah sanitasi makanan sangatlah penting, terutama di tempat-tempat umum yang erat kaitannya dengan pelayanan orang banyak. Rumah makan, restoran, hingga kantin merupakan beberapa tempat umum yang menyediakan makanan olahan yang banyak di gemari masyarakat. Keberadaan usaha rumah makan, di sisi lain dapat membantu masyarakat apalagi bagi orang-orang yang sedang dalam perjalanan ${ }^{13}$ 


\section{SIMPULAN}

Penerapan hygiene sanitasi Rumah Makan di Rumah Makan Minang Simpang Ampek panjer Kota Denpasar dengan hasil penilaian memenuhi syarat yaitu 93,33\%

\section{SARAN}

Penjamah makanan sebaiknya menggunakan sarung tangan plastik pada saat pengolahan makanan.Penyajian makanan sebaiknya menggunakan penutup makanan agar makanan tidak terkontminasi debu, serangga, rambut atau kotoran lainnya. Kemasan makanan sebaiknya menggunakan kemasa yang food grade atau aman bagi kesehatan seperti menggunakan daun pisang saat membungkus makanan.

\section{DAFTAR PUSTAKA}

1. Prasetya, E. Hygiene dan

Fasilitas Sanitasi Rumah Makan

Di Wilayah Kota Gorontalo. J.

Kesehat. Masy. FIKK Univ.

Negeri Gorontalo (2012).

2. Marapung N, Santi DN, M. I.

Hygiene sanitasi pengolahan dan pemeriksaan Escherichia

coli dalam pengolahan makanan di instalasi gizi Rumah Sakit

Adam Malik. (2012).

3. Yulia. Hygiene Sanitasi

Makanan, Minuman dan Sarana

Terhadap Angka Kuman

PPeralatan Makanan dan

Minuman Pada Kantin. $J$.

Kesehat. Lingkungan, Poltekkes

Kemenkes Pontianak (2013).

4. Rejeki, S. Sanitasi Hygiene Dan

K3. (Rekayasa Sains Bandung, 2015).

5. Hutauruk, Y. R. Sanitasi

Higiene Makanan dan Minuman

Untuk Menjaga Kualitas

Makanan dan Kepuasan Tamu

di Hotel Griya Meda. J. Mutiara

Manaj. 01, (2016).

6. Depkes. Undang-Undang

Nomor 36 Tentang Kesehatan

tahun 2009. (2009).

7. Noor, J. Metode Penelitian :

Skripsi, Tesis, Disertasi dan

Karya Ilmiah. (2011).

8. Dini Rahmadhani, S. S.

Gambaran Penerapan Prinsip

Higiene Sanitasi Makanan di PT

Aerofood Indonesia, Tangerang, 
Banten. (2017)

9. Jamaluddin, S. Gambaran

Hygiene Sanitasi Pengolahan

Makanan di Rumah Makan

yang ada di Wilayah Kerja

Puskesmas Kota. J. Kesehat.

Poltekkes Ternate (2016).

10. Departemen, K. Permenkes RI

No

1096/MENKES/PER/VI/2011

Tentang Persyaratan Higiene

Sanitasi Jasaboga. (2011).

11. Departemen, K. R. Kumpulan

Modul Kursus Higiene Sanitasi

Makanan dan Minuman. (2012).
12. Tumbelaka, C.N., S. Gambaran

Higiene Sanitasi Makanan

Ditinjau Dari Karakteristik

Penjamah Makanan Pada

Beberapa Rumah Makan Di

Kelurahan Talikuran Kecamatan

Kawangkongan Pada Tahun

2018. (2018).

13. Blongkod, F. R. Studi Hygiene

Sanitasi Rumah Makan Di

Kecamatan Kota Timur dan

Kecamatan Dumbo Raya Kota

Gorontalo. J. Kesehat. Masy.

(2012). 